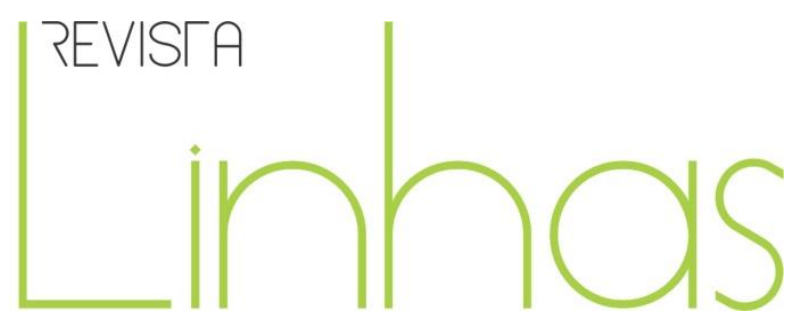

\title{
Entre correspondências e documentos: a Escola Regional de Meriti como modelo para a criação de novas instituições educacionais
}

\begin{abstract}
Resumo
O presente artigo visa examinar a influência da Escola Regional de Meriti na criação de instituições educacionais em diferentes estados brasileiros. Numa perspectiva de mão dupla, entendemos que o projeto pedagógico da instituição serviu como base para as escolas fundadas e, ao mesmo tempo, legitimou o papel desejado por Armanda Álvaro Alberto na construção de um espaço de educação para além dos seus muros e em consonância com os princípios teóricos da Escola Nova. Assim, a Escola Regional de Meriti, cujas práticas pedagógicas estavam imbricadas com os princípios do ensino regional e popular, tornou-se um modelo de organização pedagógica. Fundamental para essa análise foi a leitura dos documentos pessoais de Armanda, especialmente a correspondência que revelou a existência de uma rede de trocas de experiências e de fotos que sustentaram o processo de nascimento de instituições similares. Não se trata apenas da organização de uma memória singular, vista por Armanda Álvaro Alberto, idealizadora desse projeto educacional, haja vista que utilizamos seus documentos pessoais, mas, sim, apresenta relação com a operação historiográfica para a construção da memória social dessa instituição de ensino. Afinal, são cem anos de história. História muitas vezes esquecida pelos livros didáticos e até mesmo pelos acadêmicos e, quando lembrada, fica fadada ao esquecimento em prateleiras longe da população. Por isso, a importância da discussão do papel da Escola Regional de Meriti que sobreviveu a diferentes momentos históricos sem perder a sua relevância para a História da Educação da Baixada Fluminense.
\end{abstract}

Palavras-chave: Armanda Álvaro Alberto; Baixada Fluminense; Escola Nova; ensino regional; Escola Regional de Meriti; modelo pedagógico exemplar.

\section{Caruanã Guatara Oliveira Frescurato}

Universidade Federal Rural do Rio de Janeiro - UFRRJ - Rio de Janeiro/RJ - Brasil

vjdobf@gmail.com

\section{Fernando César Ferreira Gouvêa \\ Universidade Federal Rural do Rio de Janeiro - UFRRJ - Rio de Janeiro/RJ - Brasil gouveafcf@uol.com.br}

\author{
Para citar este artigo: \\ FRESCURATO, Caruanã Guatara Oliveira; GOUVÊA, Fernando César Ferreira. Entre correspondências e \\ documentos: a Escola Regional de Meriti como modelo para a criação de novas instituições educacionais. \\ Revista Linhas. Florianópolis, v. 22, n. 50, p. 166-190, set./dez. 2021.
}




\title{
Between correspondences and documents: the Regional School of Meriti as a model for the creation of new educational institutions
}

\begin{abstract}
It is not only about the organization of a singular memory, seen by Armanda Álvaro Alberto, creator of this educational project, since we used her personal documents, but, yes, it presents a relation with the historiographical operation for the construction of the social memory of this educational institution. After all, it is a hundred years of educational history in Baixada Fluminense. This history is often forgotten by the textbooks and even by the academics, and, when it is remembered, it is fated to oblivion on shelves far away from the population. This article aims to examine the influence of the Escola Regional de Meriti in the creation of educational institutions in different Brazilian states. From a two-way perspective, we understand that the institution's pedagogical project served as a basis for the schools founded and, at the same time, legitimized the role desired by Armanda Álvaro Alberto in the construction of an education space beyond its walls and in line with the theoretical principles of Escola Nova. Thus, the Regional School of Meriti, whose pedagogical practices were intertwined with the principles of regional and popular education, became a model of pedagogical organization. Fundamental to this analysis was the reading of Armanda's personal documents, especially the correspondence that revealed the existence of a network of exchanges of experiences and photos that supported the birth process of similar institutions. Therefore, the relevance of the discussion of the role of the Regional School of Meriti that survived different historical moments without losing its relevance for the History of Education of Baixada Fluminense.
\end{abstract}

Keywords: Armanda Álvaro Alberto; Baixada Fluminense; Escola Nova; regional education; Meriti Regional School; exemplary pedagogical model. 
O estudo sobre as instituições educativas vem aparecendo cada vez mais em pesquisas, especialmente quando se relaciona com a História da Educação no Brasil, sendo um relevante campo temático da historiografia da educação brasileira (GATTI JUNIOR, 2002). O próprio conceito e a compreensão sobre instituições escolares estão intrinsecamente relacionados à História da Educação no Brasil em que aparecem variações ao longo do tempo. A educação se dá em espaços escolares e não escolares, mesmo assim o espaço escolar é, de fato, o espaço oficial para a compreensão e a transmissão do saber daquela sociedade onde ela está inserida.

Pensar em educação e nos seus moldes ou modelos, não apenas em sua estrutura física, mas também na simbólica, que atravessa as concepções pedagógicas - como este trabalho se propõe - é sair do espaço do imediatismo e das respostas prontas.

O ser humano moderno não vive isoladamente. Logo, a prática pedagógica não pode se dissociar desse elemento, ou seja, da natureza social do homem. Pensando a educação nesse caminho de trocas, entre saberes dentro e fora da sala de aula, principalmente utilizando-se da incrível capacidade de interação com o espaço e o processo de busca e construção do conhecimento, pautado no regionalismo, a Escola Proletária de Merity avançou para um ensino inovador quando o resultado dos recursos utilizados no desenvolvimento da criança foi potencializado através das relações entre os/as alunos/as e seus/suas professores/as com práticas pedagógicas que utilizaram o meio social como ponto de interação com a prática de ensino, sendo assim, ensinaram com os elementos que faziam parte do dia a dia das crianças.

É na escola que acontecem os principais momentos de interação social para a criança. Sobretudo, durante os seus primeiros momentos de desenvolvimento social. É nesse espaço que a criança tem o seu primeiro contato social diversificado, fora do campo familiar, começando o ensaio para a criação de uma consciência coletiva e de cidadania. Indo ao encontro da ideia relacional entre escola, localidade e sociedade, Dias e Bezerra (2014) traçam um panorama de interligação entre os processos escolares e a própria região da Baixada Fluminense: 
Os processos de escolarização e o desenvolvimento das instituições culturais, contudo, não podem ser pensados de forma a isolar o objeto de suas conexões com o território e com os processos econômicos, políticos, com os mundos do trabalho, com as relações sociais produzidas de gênero, raça e classe social. Dialeticamente, não é possível compreender os diferentes movimentos de gestação dos municípios da Baixada Fluminense sem compreender as funções atribuídas à educação, em múltiplos contextos históricos. (DIAS; BEZERRA, 2014, p. 2)

Ao tecer comentários de caráter geral sobre os processos de escolarização, a partir do Ato Adicional de $1834^{1}$ e da Constituição de $1891^{2}$ até s duas primeiras décadas do século XX, no que concerne aos investimentos do Estado brasileiro na escola pública, Romanelli (1984) estabeleceu críticas a respeito do processo de descentralização das atribuições do poder central e dos demais entes públicos. Enquanto o referido Ato Adicional delegou às províncias o dever de promoverem as escolas primárias e secundárias, criou-se, na verdade, uma impossibilidade haja vista que as províncias não tinham recursos para a construção de um sistema público, o que ocasionava o abandono do ensino primário e selava o destino do ensino secundário que ficou nas mãos, em sua maioria, da iniciativa privada.

Por seu turno, a Constituição de 1891 operou, também, no caminho de uma descentralização dual do sistema de ensino: à União coube a criação de instituições de ensino superior e secundário e aos estados a organização da escola primária. Tal modelo, em tese, repetiu a dualidade presente no período imperial, sendo a escola primária a mais prejudicada em todo o processo (ROMANELLI, 1984, p. 40-41). A partir de 1920, ocorreram mudanças referentes a tal situação com o advento de diversas iniciativas pedagógicas, como a construção de prédios escolares com arquitetura específica e a preocupação com a formação docente.

[...] Foi a década das reformas educacionais. Não havia ainda um sistema organizado de educação pública, como é hoje a rede de ensino controlada pelo Ministério da Educação e do Desporto. Abriu-se assim um grande espaço para propostas em prol da educação. Um dos movimentos mais importantes da época ficou conhecido com o nome de

\footnotetext{
1 Ementa: Faz algumas alterações e adições à constituição política do Império, nos termos da Lei de $12 / 10 / 1832$.

2 Ementa: Nós, os representantes do povo brasileiro, reunidos em Congresso Constituinte, para organizar um regime livre e democrático, estabelecemos, decretamos e promulgamos a seguinte.
} 
Escola Nova. Grandes temas e grandes figuras ficaram associados a esse movimento. A defesa de uma escola pública, universal e gratuita se tornou sua grande bandeira. A educação deveria ser proporcionada a todos, e todos deveriam receber o mesmo tipo de educação. Pretendiase com o movimento criar uma igualdade de oportunidades. A partir daí, floresceriam as diferenças naturais segundo os talentos e as características de cada um. O ensino deveria ser leigo, ou seja, sem a influência e a orientação religiosa que tinham marcado os processos educacionais até então. A função da educação era formar um cidadão livre e consciente que pudesse incorporar-se ao grande Estado Nacional em que o Brasil estava se transformando. Entre os educadores que lideraram o movimento da Escola Nova estão Anísio Teixeira, da Bahia, Fernando de Azevedo e Manuel Lourenço Filho, de São Paulo. Várias reformas foram realizadas no Brasil na década de 1920: 1920 - Sampaio Dória realiza em São Paulo a primeira dessas reformas regionais do ensino; 1922-1923 - Lourenço Filho é chamado ao Ceará para realizar a segunda dessas reformas; 1924 - Anísio Teixeira traz para a Bahia a experiência que acumulou em cursos de educação nos Estados Unidos; 1925-1928 - José Augusto Bezerra de Menezes, no Rio Grande do Norte, dá continuidade ao movimento de reformas. Nos anos de 1927-1928 é a vez do Paraná, com Lisímaco Costa. Nesses mesmos anos, Francisco Campos marca o estado de Minas Gerais com seu projeto de reforma. A mais importante de todas, no entanto, foi feita no Distrito Federal, então capital da República, liderada por Fernando de Azevedo nos anos de 1927-1930. (CPDOC-FGV, 2021)

Portanto, pensar a escola, nesse tempo histórico, teve um significado de mudança. Uma busca por métodos e práticas inovadoras que instituíssem ‘o novo' em contrapartida ao método tradicional de ensino. Obviamente, num contexto histórico e político no qual o sentido da inovação tinha também a função de evitar a revolução: antes uma reforma do que uma mudança radical.

Assim, os conceitos empregados sobre instituições escolares encontram em Saviani (2005) a sinalização da relevância da materialidade da instituição escolar para atender àquela sociedade em que está inserida, produzindo e reproduzindo saberes e costumes de forma primária, mas não sendo detentora exclusiva desta atividade dentro da sociedade. Tais análises, também, estão presentes no pensamento de Nóvoa (1999), no que tange às modificações das instituições escolares ao longo do tempo, passando pelo entendimento de que para se compreender esse movimento, precisa-se ir além de sua complexidade técnica, científica e humana. 
Estudar as instituições escolares significa compreender a presença dos sujeitos que, de certa forma, contribuíram para a história e a importância da instituição, seja o/a diretor/a ou um/a professor/a com a sua prática; só assim a instituição escolar passa a ter importância para a História da Educação, não sendo mais uma na rede, mesmo que “todos os fatos educativos sejam históricos. Configurações específicas os precedem, tramas de encaminhamentos são tecidas ao longo do tempo" (WERLE; SÁ BRITTO; COLAU, 2007, p. 151). Compreende-se, dessa forma, que toda escola tem um papel expressivo na sociedade, seja em menor ou maior grau, mas para a História da Educação, nem toda instituição escolar tem distinção, sob a ótica da macro-história na perspectiva da história educacional (BARROS, 2004).

\section{De proletária à Regional de Merity: compreendendo o começo da escola}

Antes de adentrar nos aspectos relativos ao processo de difusão do projeto pedagógico da Escola Proletária de Merity para além dos seus muros, é necessário um panorama sobre o que era a Escola e sobre quem foi a sua principal idealizadora: Armanda Álvaro Alberto.

Armanda nasceu no ano de 1892, na cidade do Rio de Janeiro, oriunda de uma elite familiar, filha de Maria Teixeira Mota e Silva e do cientista Álvaro Alberto Silva, tendo como único irmão, Álvaro Alberto Mota da Silva, figura extremamente importante em sua vida. Signatária do Manifesto dos Pioneiros da Educação Nova, uma educadora que fez parte da Aliança Nacional Libertadora $(A N L)^{3}$, Associação Brasileira de Educação $(A B E)^{4}$ e uma das fundadoras da União Feminina do Brasil (UFB) 5 , e que junto com diversos

\footnotetext{
3 Organização política de âmbito nacional fundada oficialmente em 12 de março de 1935, embora sua ata de fundação seja datada do dia 23 e sua instalação pública tenha ocorrido no dia 30 . Constituiu uma frente ampla em que se reuniram representantes de diferentes correntes políticas - socialistas, comunistas, católicos e democratas - e de diferentes setores sociais - proletários, intelectuais, profissionais liberais e militares -, todos atraídos por um programa que propunha a luta contra o fascismo, o imperialismo, o latifúndio e a miséria. Foi fechada em 11 de julho de 1935, continuando a atuar na clandestinidade até a eclosão da Revolta Comunista, no mês de novembro do mesmo ano (ABREU, 2001, p. 107-109).

${ }^{4}$ A criação da Associação Brasileira de Educação em 16 de outubro de 1924 foi um acontecimento que teve importância fundamental para o direcionamento das mudanças que se fizeram no sistema educacional escolar na segunda metade da década de 1920 e, principalmente, na primeira metade da década seguinte. [...] a $A B E$ era uma sociedade civil, de adesão voluntária, que reunia professores e interessados em educação, fossem jornalistas, políticos, escritores ou funcionários públicos (XAVIER; CUNHA, 2001, p. 390391).

${ }^{5}$ Movimento político criado em maio de 1935, filiado à Aliança Nacional Libertadora (ANL). Foi fechada em 
intelectuais e colaboradores/as, implantou um sistema de educação inovador naquela localidade, unindo educação e saúde, fortalecendo assim o corpo e a mente. Ela criou um ‘celeiro' de experiências e ideias revolucionárias, a Escola Proletária de Merity, que nasceu em 13 de fevereiro de 1921, no seio da Baixada Fluminense, na Vila de Merity, hoje Duque de Caxias (RJ) 6 .

Assim, é necessário compreender que,

A Escola Proletária, adotando métodos e referências do escolanovismo, embarca no ensino regional como parâmetro de ensino e ações para as suas práticas no dia a dia, servindo, assim, como referência pedagógica para outras instituições escolares no Brasil e na América Latina. Um dos seus principais projetos é a alimentação gratuita das crianças que ali estudavam, fruto de diversas doações de moradores da região e da sua própria horta escolar, da qual seus alunos participavam ativamente, desde o plantio até a colheita. É com essa experiência que a Escola fica reconhecida carinhosamente na região como Escola Mate com Angu. $O$ projeto em seu molde original se encerra no fim do ano de 1964, pela não aceitação da incorporação da mesma na rede estadual de ensino do Rio de Janeiro, por ser considerada uma 'escola de comunistas'. (FRESCURATO; GOUVÊA, 2019, p. 23)

Ao longo da sua existência, a construção de uma rede de apoiadores/as que compartilhavam do mesmo ideal educacional se fez necessária para qualquer ambição de continuidade da Escola. À primeira vista, parece simples, basta apenas organizar as pessoas que desejam apoiar um projeto pedagógico e ir dirigindo a Escola, porém, fica evidente que a construção dessa rede foi muito mais complexa e isso se refletiu na influência que a práticas pedagógicas exerceram sobre educadores/as e instituições do Rio de Janeiro e outros estados do Brasil.

A proposta de uma escola diferente do modelo tradicional, não seguindo nenhum modelo definido (ALBERTO, 1968), fez com que Armanda Álvaro Alberto criasse uma

11 de julho do mesmo ano, juntamente com ANL, pelo Decreto $n^{\circ} 229$. Seu objetivo consistia na defesa dos interesses da mulher no Brasil, especialmente daquelas que estavam "submetidas às mais precárias condições de existência e de trabalho". Seu programa propunha a luta pelos direitos econômicos, sociais, políticos e civis da mulher, sem distinção de cor, religião, correntes filosóficas etc. (ABREU et al., 2001, p. 5.845).

${ }^{6}$ Sobre Armanda Álvaro Alberto, ver: MIGNOT, Ana Cristina Venâncio. Armanda Álvaro Alberto. In: FÁVERO, Maria de Lourdes de Albuquerque; BRITTO, Jader de Medeiros (orgs.). Dicionário de Educadores no Brasil: da colônia aos dias atuais. Rio de Janeiro: Editora UFRJ: MEC-Inep, 1999. 
escola para além do seu tempo, que nas palavras de Lourenço Filho7, foi a "mais completa experiência de educação renovada pela intenção socializadora" (LOURENÇO FILHO, 1978, p. 176).

É fato que uma criação complexa, como uma escola, não vem do acaso, é preciso além do desejo de criar, a necessidade para aquele fim. Porém, antes da criação, é preciso ter o desejo, o sonho da transformação de algo, que antes sem vida, se torna o sentido da sua existência (FRESCURATO, 2019).

E é dos sonhos que acontecem as realizações, e é assim que o funcionamento da Escola Proletária de Meriti teve o seu início no dia 13 de fevereiro de 1921, em um prédio improvisado que logo iria para outra instalação projetada por Lúcio Costa, sem fins lucrativos, totalmente gratuita para os moradores daquela localidade, sendo mantida apenas por doações de amigos/as e simpatizantes da causa educacional inovadora e também, em grande parte, pelas doações feitas pela fábrica Rupturita ${ }^{8}$ (MIGNOT, 2002; SILVA, 2003).

Em relação ao modelo pedagógico, Armanda informa:

Os programas até agora prontos ou em andamento são os de estudos da natureza, geografia, higiene e jardinagem, escritos por mim; desenho, pelo Prof. Edgar Süssekind de Mendonça; história ( $\left.1^{\circ} \mathrm{grau}\right)$, pelo Prof. Francisco Venâncio Filho; cálculo, adaptação de Paula Vera (indicação do saudoso Prof. Heitor Lyra); geometria, de Heitor Lyra e Paula Vera, pela professora da escola D. Laura Araripe; o de economia doméstica está sendo escrito por Miss Maud Mathis, do Colégio Bennett. (ALBERTO, 1968, p. 52)

Com quatro princípios básicos: 'Saúde', 'Alegria', 'Trabalho' e 'Solidariedade', a “escola ao ar livre, improvisada à sombra de bambus e com mobiliário bem tosco, inspirada na proposta montessoriana" (MIGNOT, 2010, p. 132) monta o seu projeto pedagógico, dialogando sempre nos eixos entre educação e saúde das crianças e da população em geral, os métodos de ensino levariam a criança a reconhecer a escola como

\footnotetext{
7 Sobre Lourenço Filho, ver: MONARCHA, Carlos. Lourenço Filho. Recife: Fundação Joaquim Nabuco: Editora Massangana, 2010.

${ }^{8}$ Segundo Armanda, A Rupturita S/A Explosivos, que fora instalada no $3^{\circ}$ Distrito de Nova Iguaçu, foi a principal mantedora da Regional de Merity nos primeiros anos, antes da criação da caixa escolar, quando o financiamento passa a ser aberto também para a sociedade (ALBERTO, 1968).
} 
o seu lar. O hino da escola, criado em 1930, revela como a ideia de saúde e educação eram os pilares da instituição.

\author{
Companheiros da sorte \\ Buscamos a virtude \\ Que nos torna a lama forte \\ Dando corpo e saúde \\ Somos assim felizes \\ Vivendo em harmonia \\ Hoje em nós cresce e cria \\ A profunda raiz alegria \\ A vida sem saúde \\ Trabalho, alegria e solidariedade \\ Fingindo mente, ilude \\ A quem nella confia na realidade (CARVALHO, 1930) ${ }^{9}$
}

A escola, às margens da Estação de Trem de Merity, nasceu com uma biblioteca batizada de Euclydes da Cunha, a primeira biblioteca euclidiana do Brasil (ALBERTO, 1968) e primeira biblioteca pública escolar na Baixada Fluminense ${ }^{10}$. O lugar também contava com um cinema educativo ${ }^{11}$ que passava filmes educativos para as crianças e a comunidade e com um Museu Escolar. Havia aulas de canto orfeônico ${ }^{12}$ e de ginástica sueca. A escola era aberta a todos, desde a biblioteca até o museu, e era visitada pelos moradores de Merity, o que fomentou as sementes da ligação entre escola e comunidade. A escola era mantida pela firma Venâncio \& Cia, que controlava a fábrica de Rupturita. O dono era seu irmão, Álvaro Alberto13. A instituição era também mantida

\footnotetext{
9 Hino da Escola Regional de Merity escrito por Mário Marques de Carvalho em 1930. Arquivo de Armanda Álvaro Alberto.

${ }^{10}$ Leonel de Moura Brizola criou no Rio de Janeiro os Centros Integrados de Educação Pública (CIEPs) com a implantação do projeto de Darcy Ribeiro. Escolas em tempo integral com bibliotecas para a comunidade (RIBEIRO, 1986). O interessante desse projeto é que quase todos os aspectos se assemelham ao projeto de Armanda Álvaro Alberto, desde a oferta de merenda até o ensino integral, passando por atividades complementares à formação; porém, o projeto de Armanda durou muito mais tempo do que o de Brizola no Rio de Janeiro por conta da falta de continuidade política dos seus sucessores no governo do Estado.

${ }^{11}$ As primeiras sessões de cinema só foram acontecer em 1934 com a chegada da energia elétrica no município.

${ }^{12} \mathrm{O}$ início das aulas de canto orfeônico ocorreu em 1944.

${ }_{13}$ Álvaro Alberto da Mota e Silva nasceu no Rio de Janeiro em 22 de abril de 1889. Em 1911, ingressou na Escola Politécnica do Rio de Janeiro, onde diplomou-se engenheiro [...] foi presidente da Sociedade Brasileira de Química de 1920 a 1928. Representante brasileiro na Comissão de Energia Atômica da ONU, seu
} 
pelos diversos/as colaboradores/as; portanto, uma escola que não era mantida pelo Estado.

Armanda, havia muito tempo, já esboçava um pensamento de que educação e saúde andam entrelaçadas, numa época em que o impaludismo e as doenças, como a malária, assolavam a população local. Mignot (1993) descreve a situação da Vila Merity, hoje Duque de Caxias, nas décadas de 1920 e 1930.

O cenário onde se desenvolveu o trabalho pedagógico de Armanda Álvaro Alberto e seus colaboradores foi descortinado nos relatórios anuais. A Baixada Fluminense, em 1921, vivia em declínio econômico, faltava saneamento, proliferavam charcos insalubres e doenças como a malária - resultado do descaso governamental nos primeiros anos da República. Os relatórios registravam, ao longo dos anos, não só as dificuldades e conquistas pedagógicas, mas revelavam, sobretudo, as condições de vida da comunidade. Epidemias de sarampo, coqueluche, casos de tuberculose, surtos de impaludismo, conviviam com ausência de Posto de Profilaxia Rural, guarda sanitário, vacinas, medicamentos, assistência médico/odontológica, água encanada, rede de esgotos, instalações sanitárias, iluminação e transporte. Assinalavam ainda o aumento populacional, a miséria e a violência decorrente da ocupação de terras a partir de 1930. (MIGNOT, 1993, p. 625)

Nesse sentido, o campo no qual estava inserida a Escola propiciava os métodos pedagógicos ao ar livre e outras técnicas vindas ao auxílio do ensino. Se pensarmos no campo mais amplo da pedagogia institucional da Escola, ocorreu uma nova experiência em um novo campo, como salienta Mignot.

[...] Meriti, zona rural, em 1921, permitiu à Armanda atender as crianças provenientes das camadas populares, numa escola nova, diferente que servisse de exemplo, sendo um "laboratório de pedagogia prática". Essa concepção de escola experimental, escola-laboratório, diferente de escola-modelo, visava dar à educação o mesmo estatuto dos laboratórios em relação às ciências físicas, como preconizava Dewey. (MIGNOT, 2002, p. 184)

nome foi indicado por unanimidade para a presidência desse organismo no biênio 1946-1947. [...]. Presidente do Conselho Nacional de Pesquisas (CNPq) no período de 1951 a 1955 (COUTINHO, 2001, p. 6566). 
O periódico “O Jornal” também anunciou o programa de ensino da Escola Regional de Merity dividido em quatro segmentos: nos três primeiros se aprendiam linguagens, desenho, cálculo, jogos e cânticos infantis, Geografia e História brasileira, tudo indo ao encontro do modelo da Escola Nova. Já no quarto segmento, os trabalhos eram voltados para a oficina, permanecendo assim, a instrução mais técnica. Além disso, havia excursões para os jardins públicos e para museus, em todo o Rio de Janeiro (O JORNAL, 7 de julho de 1927). Passeios escolares, que atualmente chamamos de visitas técnicas, como por exemplo, ao Jardim Botânico e ao mar, fizeram parte da vida escolar das crianças, assim como o cuidado com a saúde, uma vez que a escola contava com um posto médico que atendia não só as crianças, mas toda a comunidade.

Os passeios não ocorriam só pela região de Meriti, mas, também, para outras localidades. Esse conceito se aproxima do trabalho que Freinet desenvolveu ao longo da sua carreira. Primeiro com as aulas passeio, nas quais a criança participava ativamente no aprendizado e trabalhava com elementos que faziam parte da localidade visitada (FREINET, 1977). Segundo, com o conceito de escola ativa, principalmente na questão do ensino, que passava pelas ciências naturais, pela matemática e até a linguagem era trabalhada nos moldes da diversidade que os/as alunos/as apresentavam. Fez-se presente, ainda, a questão do conceito da escola ser a extensão do lar, como afirma Freinet.

[...] a escola deveria ter belos jardins cujas plantas extraem, num solo rico, a mesma seiva, mas onde desabrocham segundo a sua natureza e a sua utilidade, os legumes úteis, as árvores generosas e as flores da poesia e da beleza, tão necessárias por vezes como os alimentos fundamentais. (FREINET, 1973, p. 50)

Freinet (1977) entendia que a escola deveria se adaptar ao meio em que ela estava inserida, fazendo isso, tanto nas concepções pedagógicas, quanto nos materiais utilizados no processo de ensino e aprendizagem, a criança teria um aumento no aproveitamento. Porém, Armanda foi além; para ela, a escola deveria se adaptar ao meio para o sucesso da permanência das crianças na instituição, pois a aproximação da escola com a sociedade meritiense não se deu apenas por uma questão puramente pedagógica, se deu por uma questão de sobrevivência e sucesso daquele projeto idealizado. Cabe 
levantar que essa aproximação deu sentido ao que se ensinava às crianças, pois elas iriam utilizar a aprendizagem no cotidiano para a superação das adversidades.

Ao contar a história da escola, conta-se o processo pedagógico revolucionário que colocou essa mesma instituição na história educacional brasileira: a primeira instituição de educação que se tem notícia, até o presente momento, a ter um museu escolar, um cinema e uma biblioteca na Baixada Fluminense, uma das primeiras da América Latina que se tem notícia a oferecer merenda aos seus alunos e o ensino regional como a sua principal característica (ALBERTO, 1968).

Também é importante repensar o papel social e educacional dessa escola, essencialmente no período pós-30, momento em que foi publicado o Manifesto dos Pioneiros da Educação Nova de 1932, do qual Armanda fora signatária, levantando a possibilidade de a experiência educacional da Escola Proletária de Merity ter influenciado na elaboração desse importante documento para a educação brasileira pois, a grande parte, senão a maioria, das instituições escolares apareceria como um espaço estratégico de disseminação dos valores e princípios conformadores da nova ordem social em construção.

Portanto, uma escola centenária que não é um patrimônio histórico apenas para os moradores de Duque de Caxias, município do estado do Rio de Janeiro, mas também um patrimônio da história educacional do Brasil: Escola Proletária de Merity, Escola Regional de Meriti e Escola Mate com Angu uma instituição de ensino que teve o seu projeto pedagógico legitimado para além da Baixada Fluminense do estado do Rio de Janeiro.

\section{O projeto educacional para além dos muros: um modelo pedagógico exemplar}

O objetivo primário de contar a história e a consolidação do processo pedagógico da Escola Proletária de Merity e o seu próprio fortalecimento segue os fios de memória, pois “na construção da memória, lembra-se esquecendo, esquece-se lembrando" (ROLLEMBERG; MARTINS FILHO, 2006, p. 7). 
Dentro da literatura educacional, a menção sobre a experiência na Regional de Merity não veio apenas de sua idealizadora. Sempre recordando a memória, através de documentos escolares, unindo várias memórias, o de quem a construiu direta ou indiretamente, vivendo o cotidiano da escola e a contada por notícias e relatórios, não deixando de salientar o fato de que não se trata apenas da organização de uma memória singular, vista por Armanda. A pesquisa utilizou os seus documentos pessoais na perspectiva de construção da memória social dessa instituição de ensino.

\begin{abstract}
Quando recordamos, agimos individualmente. Essas lembranças, quando são reveladas e socializadas, tornam-se fatos sociais. A memória individual torna-se então memória social. Ou memória coletiva. Uma das funções sociais dessa memória é dar uma identidade aos grupos que a produzem. Nesse sentido, em uma sociedade não existe uma memória, e sim múltiplas, tantos quantos forem os grupos que a compõem. (SILVA, 2003, p. 53)
\end{abstract}

Ao passo que o projeto educacional era executado, as informações e os resultados começaram a ser em divulgados para outros/as educadores/as. Sobre isso, registra-se a apresentação da Escola em um artigo amplamente divulgado na Revista Educação no ano de 1925, escrito por Edgar Sussekind de Mendonça ${ }^{14}$ e Francisco Venâncio Filho ${ }^{15}$ (ALBERTO, 1925); a apresentação da Escola Regional em forma de tese na I Conferência Nacional de Educação promovida pela ABE em Curitiba, no ano de 1927, junto com a moção de aplausos no mesmo evento; em 1930, na obra de Lourenço Filho sobre a Escola Nova no Brasil, sendo um capítulo destinado à experiência na Regional de Merity (LOURENÇO FILHO, 1978); em 1932, a Escola foi apresentada na V Conferência da ABE, a sua experiência consolidada, constando nas atas do evento e em outros documentos posteriores à assinatura, que essa experiência educacional com o sucesso esperado, influenciou no conteúdo do Manifesto dos Pioneiros da Educação Nova (ALBERTO, 1968),

\footnotetext{
${ }_{14}$ Para mais informações sobre Edgar Sussekind de Mendonça, ler: VIDAL, Diana Gonçalves. Edgar Sussekind de Mendonça. In: FÁVERO, Maria de Lourdes de Albuquerque; BRITTO, Jader de Medeiros (orgs.). Dicionário de Educadores no Brasil: da colônia aos dias atuais. Rio de Janeiro: Editora UFRJ/MEC-Inep, 1999.

15 Sobre Francisco Venâncio Filho, ler: SUCUPIRA, Newton Lins Buarque. Francisco Venâncio Filho. In: FÁVERO, Maria de Lourdes de Albuquerque; BRITTO, Jader de Medeiros (orgs.). Dicionário de Educadores no Brasil: da colônia aos dias atuais. Rio de Janeiro: Editora UFRJ/MEC-Inep, 1999.
} 
entre as diversas matérias jornalísticas de revistas especializadas em educação e os jornais que circulavam na região.

Toda essa movimentação de informações sobre a Regional de Merity despertou o interesse de outros profissionais ligados à educação brasileira e até mesmo dentro das Américas. A Escola Regional de Merity não manteve as suas atividades pedagógicas apenas entre os seus muros. O anseio por uma educação de qualidade, desejo de Armanda Álvaro Alberto, não poderia ficar apenas naquele espaço, pois a Regional era um laboratório educacional para os ideais que preconizavam o modelo escolanovista no Brasil. Tal perspectiva foi alcançada mediante o encontro de documentos e correspondências que atestaram as influências exercidas pela Escola Regional de Merity na criação de outras instituições: no Rio de Janeiro tivemos, por exemplo, a criação da Escola Municipal Sagrada Família de Nazareth, no distrito de Andrade Costa, na zona rural do município de Vassouras, nos moldes pedagógicos da Escola Regional de Merity ${ }^{16}$. Essa influência torna-se evidente na correspondência enviada por Helena Dale para Armanda:

[...] O projeto dessa escola inspirado na Escola Regional de Meriti foi realizado pelo Sr. João Dale, com o nome de Escola Sagrada Família de Nazaré. Integra, hoje, a mais importante obra social da região, que é a Associação Maternidade e Infância de Andrade Costa, Município de Vassouras, no Rio. (DALE, 1925, sp.) 17 $^{17}$

Ao visitar a escola, pode-se constatar nhoque mantém o mesmo formato arquitetônico desde a sua criação, lembrando uma grande fazenda, com salas abertas ao ar livre, grandes janelas, jardim para a horta que os próprios/as alunos/as cuidavam. Seu processo também se assemelha ao da Regional, até a sua doação para o Estado, neste caso, concretizada em novembro de 1972, depois passando a ser municipalizada no ano de 1988.

A Escola Regional continuou a inspirar novas experiências, como foi a de Monte Aprazível. Monte Aprazível fica no interior do Estado de São Paulo. Deixando de ser

\footnotetext{
${ }^{16}$ A instituição foi criada 1927 e construída no mesmo terreno da Igreja Sagrada Família de Nazareth, pertencente a José Lemos e Basilina de Almeida, esta, professora na escola Regional em período posterior, de 1941 a 1945.

${ }^{17}$ A grafia original será mantida em todas as cartas.
} 
distrito de São José do Rio Preto, nasceu como município graças à Lei Estadual nº 2008 de 23 de dezembro de 1924. De 1934 até o ano de 1941, a troca de correspondências foi constante. O conteúdo das missivas girava em torno das seguintes questões: a estruturação da Regional de Merity, o programa da Escola e manutenção financeira.

As correspondências foram enviadas para o professor Tasso do Amaral Botelho e para o Secretário de Educação Luis Neves, que se interessam pela experiência da Regional de Merity, como consta em carta enviada por Luiz Neves para Armanda.

Prezada $S^{a}$ Armanda Alvaro Alberto

De fato a escola que mantém em Meriti muito nos interessa. Daí ter resolvido enviar-lhe a que lhe chegou ás mãos, por intermédio do Prof. Lourenço Filho.

Sou amigo do Prof. Tasso Botelho. Eu e ele pretendemos, depois de bem conhecida a sua escola, fundar aqui uma que a imite. Para isso temos necessidade de conhecer os meios como adquire recursos para sustentala, assim como a proteção social que a mesma dá às mães e irmãs das alunas. Em suma, desejamos os esclarecimentos julgados convenientes para ter-se exata compreensão do que é essa escola, merecedora de gerais elogios, mas mal estudada por todos professores ou publicistas, que se referem a ela.

[...] Como temos, porem, urgência de dar inicio a nossa escola, ficamos certos de que não deixará de dar-nos a orientação que necessitamos.

Desde já agradecido,

Luiz Neves (NEVES, 1939, p. [1) $]^{18}$

A instituição escolar, idealizada por Luiz Neves e Tasso Botelho foi criada em 1940, com o nome de Ateneu Aprazivelense. Pesquisando mais sobre a escola, encontra-se a seguinte notícia do jornal "A Cidade", datada de 30 de junho de 1940, na qual o redator Constantino de Carvalho relata a fundação do Ateneu Aprazivelense:

Sob a direção do professor Luiz Neves e com ótimos professores, será aberto amanhã, $1^{\circ}$ de julho, o Ateneu Aprazivelense, que inicialmente se destina a ensinar o curso preparatório para admissão ao ginásio, e que será o embrião do futuro Ginásio de Monte Aprazível. (CARVALHO, 1940, p. 2)

\footnotetext{
18 NEVES, Luiz. [Carta] 07 de set. 1939, São Paulo [para] ALBERTO, Armanda, Rio de Janeiro. 3f. Solicita informação sobre o modelo de ensino da Escola Regional de Meriti.
} 
São escassas as informações sobre a instituição e, especificamente, quanto ao modelo educacional adotado. Mas, ao fazer a análise no conteúdo das cartas trocadas ao longo dos anos, pode-se presumir que a instituição de Monte Aprazível tentou seguir o mesmo modelo educacional da Regional de Merity. A instituição se transformou em Ginásio Municipal de Monte Aprazível em 1941, sendo atualmente gerido pela Sociedade Civil de Ensino Dom Bosco, de Monte Aprazível, virando Faculdade Dom Bosco, de caráter privado.

Outra instituição que promoveu as atividades que aconteciam na Regional foi a Sociedade dos Amigos de Alberto Torres. Torna-se necessário assinalar que o pensamento de Alberto Torres, em determinado momento, seguiu uma linha diferente das pessoas que criaram a associação com o seu nome. Alberto Torres pregava o nacionalismo; a população deveria adorar a terra onde nasceu. Nesse sentido, o regionalismo seria a forma ideal de educação, começando pelos mais jovens.

\begin{abstract}
A associação de indivíduos e famílias que habitam o Brasil com ânimo de permanência, protegidos pelo conjunto dos órgãos da sua política: 0 "Estado"; formando, sobre seu habitat territorial: o "País", graças à consciência de uma continuidade histórica de heranças morais e materiais e de uma simpatia e comunidade entre os vivos, uma agremiação fundada sobre a confiança em certas condições práticas de tranqüilidade e de segurança, superiores à vontade e ao poder de cada um de seus membros - uma "Pátria”. (TORRES, 1982, p. 27)19
\end{abstract}

Com isso, o conceito de nação era empregado como forma agregadora dos indivíduos dentro da sociedade, como iguais, sem distinção de raça ou classe social, fugindo de qualquer modelo de sociedade fora da brasileira.

Em um primeiro momento, a Sociedade dos Amigos de Alberto Torres teve duas correntes, uma pautada na educação regional, levando o conceito de saúde e higiene para a escola rural e outra corrente que acreditava que primeiro era imprescindível a construção da identidade nacional brasileira, que deveria ser constituída de uma raça única (MAIO, 2010), engessada no determinismo racial, tese defendida por Oliveira Vianna, principal articulador de tais ideias dentro da Sociedade.

\footnotetext{
${ }^{19}$ Grifos do autor.
} 
Criada em 10 de novembro de 1932, na cidade do Rio de Janeiro, a Sociedade dos Amigos de Alberto Torres foi um espaço para troca de experiências e promoção do regionalismo. Se, por um lado, existia Oliveira Vianna, com todo o seu pragmatismo de supremacia ariana, por outro, existiam as figuras de Roquette Pinto, Armanda Álvaro Alberto, Teixeira de Freitas, defendendo o potencial que o ensino poderia revelar para solucionar os problemas brasileiros, a valorização da cultura regional e do povo brasileiro.

Incentivando diversas atividades que reconheciam, além da cultura regional, questões de saúde e higiene, a Sociedade dos Amigos de Alberto Torres promoveu conferências e eventos para auxiliar a formação de núcleos regionais, espalhados pelo Brasil. Uma dessas atividades desenvolvidas foi o concurso de Janelas Floridas, criado dentro da Regional de Merity, como mostra o Diário Carioca, em 17 de agosto de 1963.

Torres defendia que era preciso conhecer o interior brasileiro, pois seria lá que iríamos fomentar o desenvolvimento econômico mas, para isso, era preciso levar o saneamento e a educação para essas localidades (TORRES, 1982). Esse discurso se aproximava do pensamento de Belisário Penna e do movimento higienista, os quais pregavam que a educação e a saúde não poderiam andar separadas, pois eram as principais prioridades de qualquer governo brasileiro (PENNA, 1923). Por isso, não poderia ser uma escola típica da cidade transportada para o campo; deveria ser uma escola do campo e para o campo, mas não bastava apenas focar na formação dos/as alunos/as, o enfoque também passaria pela formação docente, que deveria ter o objetivo de levá-los a conhecer como é a vida no campo (PRADO, 2013).

A troca de experiências, de como as atividades eram desenvolvidas na Regional de Merity, inspirou a criação da Escola Rural Modelo de Tigipió, no Ceará, experiência contada por Orlando Carvalho em ‘Ensaio de Politica e Economia' lançado no ano de 1933.

[...] assim sendo, a escola rural é uma necessidade premente, não só porque o filho do lavrador terá instrução sem precisar abandonar o campo, este, maior medo da população do campo. Algo que só aconteceu na Escola Regional de Merity, escola do Rio de Janeiro, modelo inspirador da Escola Rural Modelo Alberto Torres de Tigipió, na cidade de Aracoiaba, bem no interior de Fortaleza. (CARVALHO, 1933, p. 72) 
De fato, ao observar o modelo escolar que as duas escolas seguiam, encontra-se semelhança nas suas formas de atuação, que apresentam a vida no campo como princípio norteador das atividades pedagógicas. Na Escola Rural de Tigipió, o clube de atividades rurais tinha o mesmo objetivo do Círculo das Mães e do Clube Rural da Escola Regional de Merity.

Na direção da Escola Rural de Tigipió estava Maria do Carmo Ramos Pinto Ribeiro, professora que participou dos cursos para formar professores especialistas no ensino regional, promovidos pela Sociedade de Amigos de Alberto Torres. Segundo Maria do Carmo, a Escola Rural se tornou a principal instituição dentro de Fortaleza em que se abordava o trabalho no meio rural, além das questões de higiene, civismo, cultura e a formação moral do indivíduo, sendo que a higiene e a educação rural os principais pilares da instituição (RIBEIRO, 1941).

Na região do Ceará também foi encontrada mais uma evidência da influência do projeto da Regional de Merity, através da figura do professor Joaquim Moreira de Souza ${ }^{20}$, ou apenas Moreira de Souza, como era conhecido.

\begin{abstract}
Da. Armanda
Cumprimente-a

Com muita satisfação, agradeço-lhe a remessa das fotografias, destinadas aos grupos escolares do Ceará, aos quais já foram enviadas.

No intuito de que se estabeleça franca e cordial relação entre os escolares cearenses e os da Escola de Meriti, estou a pedir, mui encarecidamente, empregue a Sra. os seus bons ofícios no sentido de que os alunos desse modelar estabelecimento enviem correspondência aos dos nossos grupos escolares da Capital.

Por mais esse obséquios, nós, os educadores desta terra, lhe seremos gratíssimos, e o Ceará lhe será ainda mais devedor.

Com os protestos de alta consideração, apresento a Sra. e ao Edgard as minhas cordiais saudações. (SOUSA, 1924, s.p.)
\end{abstract}

A troca de correspondência entre Moreira Sousa e Armanda evidencia o desejo de relacionar as experiências educacionais um com o outro. O fato culminou na visita do educador à Regional de Merity no ano de 1924 para conhecer melhor o projeto. Essa troca

\footnotetext{
20 Cabe aqui uma observação quanto à grafia do nome do professor. Nas cartas endereçadas a ele, Armanda escrevia Moreira de Souza, com " $z$ ", mas o nome correto era Moreira de Sousa, com "s", igual às cartas que ela recebia do professor.
} 
de experiências foi fundamental para a educação no Ceará, como nos apresenta Tavares (2014); experiência que influenciou o pensamento educacional da região.

Essa mistura de influências viria desde a reforma educacional proposta por Antonio Carneiro Leão, em 1927, até a gestão do modernista Annibal Bruno à frente da Diretoria Técnica de Educação, responsável pela criação da escola em questão no "governo revolucionário" de Carlos de Lima Cavalcanti, instalado em 1930 e interrompido depois da Intentona Comunista, em 1935. (TAVARES, 2014, p. 149)

Após 10 anos da visita do professor Moreira Sousa e a troca de várias correspondências $^{21}$, pelo Decreto 1.218, de 10 de janeiro de 1934, foi criada a Escola Normal Rural de Juazeiro do Norte (ENRJN) na região rural de Ceará, quando Moreira de Sousa se tornou Diretor Geral de Ensino do Ceará (CASTELO, 1951).

Entre as semelhanças com o projeto da escola idealizada por Armanda Álvaro Alberto e da escola do professor Moreira Sousa, ficou em evidência o Museu Pedagógico, que mostrava as atividades realizadas na ENRJN, criado graças à leitura do Relatório Anual de 1923 da Escola Proletária de Merity (SOUSA, 1934). Porém, segundo Sousa, ele conseguiu ir além do projeto no qual se inspirou, não pensando apenas na formação do estudante, mas na necessária formação do corpo docente, em um processo de preparação destes para a formação estudantil, formando pessoas para a vida rural, gerando riqueza para o Nordeste (SOUSA, 1934).

Ao analisar toda a documentação, entre cartas, memorandos e citações nos relatórios anuais, a proposta que mais se assemelhou ao praticado pela Escola Regional de Merity foi a desenvolvida por Moreira Sousa, não só pelo aspecto arquitetônico, com o Museu Escolar, mas pelo projeto educacional desenvolvido, remetendo ao Regionalismo como princípio ativo formador de alunos/as e professores/as.

\footnotetext{
${ }^{21}$ Foram no total de 14 correspondências encontradas e utilizadas para a elaboração do artigo.
} 


\section{Considerações finais}

O que de fato podemos aprender com a história pedagógica na Regional de Merity? A primeira lição é que jamais esteve no seu tempo. Enquanto se pensava em um modelo educacional para o país, como se revelou no Manifesto de 1932, na Regional de Merity já se pensava em como garantir a permanência daquele/a aluno/a em período integral na escola, com saúde, alimentação, vestuário e diversas atividades, não ficando presa/o apenas ao conteúdo formal. Ser chamada de Mate com Angu mostra que a Regional de Merity era uma escola viva, como anunciou Carlos Drummond de Andrade. Um projeto admirado pelos mais diversos segmentos da sociedade.

A figura de Armanda Álvaro Alberto mostra que a educação está para além da sala de aula, além das quatro paredes, está além da vida cotidiana das pessoas. Sua influência foi determinante no sucesso e na duração ao longo dos anos de tudo o que acontecia ali. Não teve medo de dialogar com Tenório Cavalcanti, nem da prisão que Getúlio Vargas tentou impor como forma de 'apagar' as suas ideias, pensando que calaria a voz da educadora. Porém, essa situação foi capaz de gerar o maior testemunho da educadora, através de uma carta aos/às seus/suas alunos/as, só pensava em saber como estavam os seus 'passarinhos', forma carinhosa pela qual chamava os/as alunos/as, inclusive, incentivando as eleições estudantis dentro da Escola, algo que não se via no meio político comandado pelo mesmo Vargas.

Dentro dessa perspectiva, a rede de colaboradores foi fundamental para o sucesso do projeto educacional que ali estava nascendo. Não se pode separar a pessoa Armanda da Escola Regional de Merity, da mesma forma que não se separa a escola do meio social onde ela estava inserida, a região de Iguassú, que logo se transformaria em Duque de Caxias. A região de Merity foi o espaço social ideal para o projeto que estava se propondo, uma região que nasceu rural, mas que, com o tempo, teve demandas do mundo urbano; uma região que não tinha conhecimento sobre a relação entre saúde e higiene, mas que através da Escola, começou a ter.

Em uma ampla análise, os relatórios anuais, distribuídos entre os mais diversos segmentos, contribuíram significativamente para a manutenção da Escola e para o elevado número de colaboradores. Com uma gama de informações, os relatórios 
serviram como fontes primárias, secundárias e até terciárias, dependendo da informação que se buscava, ratificada pelas inúmeras fotografias, comprovando as ações que se realizavam na Escola. Esse documento se mostrou como o caminho pelo qual Armanda dialogava com a sua rede de colaboradores, indicando as suas demandas, sucessos, fracassos e o que poderia melhorar ou aprimorar, determinando as suas ações de acordo com as suas necessidades.

O escolanovismo, representado pelo regionalismo ali não era alienante, se apresentou com elementos de busca pelo saber, pela mudança social, pelas causas populares, uma mudança que partiu do micro para o macro. A própria população do entorno da Escola mostrou que não era passiva, que não aceitaria qualquer condição para a educação, fato que fez com que a Regional de Merity fosse coerente com os anseios da região ao longo dos anos, como foi revelado nos relatórios anuais.

Os diversos concursos e ações, como a oficina de artes manuais e o Círculo das Mães tiveram papel, tanto na mudança social, quanto na transformação da mentalidade das pessoas. Nesse sentido, a educação não foi horizontal, apenas proposta pela intelectualidade que dirigia a Escola. Momentos de tensões ocorreram na convivência da população de Merity, desconfiada em relação ao projeto que se iniciava mas que, aos poucos, compreendeu que o que se fazia era em prol da população da região, como a professora visitadora, a farmácia escolar e as noções de higiene e saúde que eram empregadas.

Armanda certamente merece um papel maior dentro do bojo da história educacional brasileira; mesmo com as recentes pesquisas sobre a sua vida e a sua obra dentro da educação, algumas lacunas ainda persistem em não serem preenchidas. Preliminarmente, dentro do campo pesquisado, ela se mostrou uma educadora que foi mais de ação do que de teorização; seu espaço de trabalho não possuiu uma fórmula pronta, mas não tinha improvisação, apenas adaptação, isso foi o que manteve todos os sonhos vivos, seus sonhos educacionais.

A história da escola baseada do Regionalismo como princípio pedagógico, nos pilares de "Saúde”, “Alegria”, “Trabalho" e "Solidariedade”, também merece destaque na historiografia brasileira. Uma escola que nasce Proletária transforma-se em Regional, mas que fica conhecida como 'Mate com Angu', marca da sua própria pedagogia, de que 
só se poderia ensinar a uma criança, quando ela estivesse alimentada e com saúde, também merece um estudo aprofundado, com o retorno ao regionalismo com as características presentes na própria região, principal forma para a compreensão da realidade local, compreendendo que a educação não é neutra, nem o seu conjunto de ações.

Epistemologicamente, buscar o resultado do trabalho feito no chão da escola deverá ser principio norteador de outras pesquisas sobre o tema. Entretanto, com o aprofundamento das múltiplas fontes pesquisadas, os relatórios anuais, as cartas, os memorandos e as revistas pedagógicas, vale destacar que, de forma simbólica, a feitura do caminho foi mais importante do que o resultado.

Assim, é imprescindível que se faça uma reflexão mais aprofundada a respeito de todo o processo pedagógico que a Escola conseguir exercer ao longo de quase 44 anos em seu molde original, além disso, uma busca refinada de todas as escolas que sofreram influência direta ou diretamente da experiência que estava sendo trabalhada naquele espaço. Um estudo aprofundado sobre essa rede de iniciativas escolares pelo Brasil poderá trazer resultados significativos para a historiografia educacional brasileira, principalmente no campo da História da Educação, a fim de que mais 'páginas' sejam construídas, elaboradas e pensadas sobre a centenária Escola Regional de Merity.

\section{Referências}

A ESCOLA Regional de Merity. O Jornal, Merity, p. 04, 1927.

ABREU, Alzira Alves. Aliança Nacional Libertadora. In: ABREU, Alzira Alves et al. Dicionário histórico-biográfico brasileiro pós 1930. Rio de Janeiro: Editora FGV/CPDOC, 2001. v. 1. p. 107-109.

ABREU, Alzira Alves. União Feminina do Brasil. In: ABREU, Alzira Alves et al. Dicionário histórico-biográfico brasileiro pós 1930. Rio de Janeiro: Editora FGV/CPDOC, 2001. v. 5. p. 5.845 .

ALBERTO, Armanda Álvaro. A escola regional de Meriti. Rio de Janeiro: INEP-MEC, 1968.

ALBERTO, Armanda Álvaro. Relatório Anual. In: A ESCOLA PROLETÁRIA DE MERITY NO ANO DE 1925. São João de Merity, p. 10-11. 
BARROS, J. D’Assunção. 0 campo da história: especialidades e abordagens. Petrópolis: Vozes, 2004.

CARVALHO, Constantino. Fundação do Ateneu Aprazivelense. A Cidade, Aprazível, p. 2-2, 30 jun. 1940.

CARVALHO, Mário Marques. [Hino da Escola Regional de Merity]. São João de Merity. Relatório A Escola Regional de Merity no ano de 1930.1930.

CARVALHO, Orlando Magalhães. Problemas fundamentaes do municipio. São Paulo: Companhia Editora Nacional, Coleção Brasiliana, 1933.

CASTELO, Plácido Aderaldo. 0 ensino rural no Ceará. Fortaleza: Editora Instituto do Ceará, 1951.

COUTINHO, Afrânio. Álvaro Alberto. In: ABREU, Alzira Alves et al. Dicionário históricobiográfico brasileiro pós 1930. Rio de Janeiro: Editora FGV/CPDOC, 2001. v.1.

DALE, Helena. [Correspondência]. Destinatário: Armanda Álvaro Alberto. [S. I.], 1925. 1 carta pessoal.

DIAS, Amália; BEZERRA, Nielson. História da educação na Baixada Fluminense: redes educativas e processos de escolarização. Recôncavo: Revista de História da UNIABEU, Nova Iguaçu, v. 4, n. 6, p. 1-5, 2014.

FRESCURATO, Caruanã Guatara Oliveira. Na tropicália dos excluídos um projeto educacional se consolida: a escola proletária de Merity e o seu modelo de educação (19211964). 167 f. 2019. Dissertação (Mestrado em Educação) - Universidade Federal Rural do Rio de Janeiro, Seropédica, Rio de Janeiro, 2019.

FRESCURATO, Caruanã Guatara Oliveira; GOUVÊA, Fernando César Ferreira. Entre histórias e arquivos na Proletária de Merity: trabalhando conceitos com a memória de seus relatórios anuais entre 1921 até 1948. MÉTIS: história \& cultura, Caxias do Sul, v.18, n. 36, p. 15-34, jul./dez. 2019.

FREINET, Célestin. 0 método natural II: a aprendizagem do desenho. Lisboa: Estampa, 1977.

FREINET, Célestin. Para uma escola do povo. Lisboa: Ed. Presença, 1973.

FUNDAÇÃO GETÚLIO VARGAS. Centro de Pesquisa e Documentação de História Contemporânea do Brasil. Dossiê: A Era Vargas: dos anos 20 a 1945. Temática: Anos 20, Questão Social, Reformas Educacionais. Rio de Janeiro: FGV/CPDOC. Disponível em: https://cpdoc.fgv.br/producao/dossies/AEraVargas1/anos20/QuestaoSocial/ReformasEduc acionais Acesso em: 17 de jun. 2021. 
GATTI JUNIOR, Décio. A história das instituições educacionais: inovações paradigmáticas e temáticas. In: ARAÚJO, José Carlos Souza; GATTI JUNIOR, Décio (org.). Novos temas em historia da educação brasileira: instituições escolares e educação na imprensa. Campinas: Autores Associados; Uberlândia: EDUFU, 2002. p. 3-24.

JANELAS floridas. Diário Carioca, p. 5, 17 agosto, 1963.

LOURENÇO FILHO, Manuel Bergström. Introdução ao estudo da escola nova. 12. ed. São Paulo: Melhoramentos; Rio de Janeiro: Fundação nacional de material escolar, 1978.

MAIO, Marcos Chor; SANTOS, Ricardo Ventura. Raça como questão: história, ciência e identidades no Brasil. Rio de janeiro: Editora FIOCRUZ, 2010.

MIGNOT, Ana Chrystina Venâncio. Armanda Álvaro Alberto. Recife: Fundação Joaquim Nabuco: Editora Massangana, 2010.

MIGNOT, Ana Chrystina Venâncio. Baú de Memória, bastidores de histórias: o legado pioneiro de Armanda Álvaro Alberto. Bragança Paulista: EDUSF, 2002.

MIGNOT. Ana Chrystina Venâncio. Decifrando o recado do nome: uma escola em busca de sua identidade pedagógica. Revista Brasileira de Estudos Pedagógicos, Brasília: Instituto Nacional de Estudos e Pesquisas Educacionais, v. 1, n. 1, p. 619-638, set./dez. 1993.

MANIFESTO DOS PIONEIROS DA EDUCAÇÃO NOVA. Revista Brasileira de Estudos Pedagógicos, Brasília, v. 65, n. 150, p. 407-425, maio/ago. 1984.

NEVES, Luiz. [Correspondência]. Destinatário: Armanda Alberto. São Paulo, 07 de set. 1939. 3 f. 1 carta pessoal.

NÓVOA, António. Para uma análise das instituições escolares. As organizações escolares em análise, Lisboa: Publicações Dom Quixote / Instituto de Inovação Educacional, v. 3, p. 13-43, 1999. PENNA, Belisário. Saneamento do Brasil. 2. ed. Rio de Janeiro: Ribeiro dos Santos, 1923.

PRADO, Adonia Antunes. Ruralismo pedagógico no Brasil do Estado Novo. Estudos Sociedade e Agricultura, Seropédica, v. 3, n. 1, p. 5-27, 2013.

RIBEIRO, M. C. R. P. O movimento ruralista em Pernambuco. Revista de Educação, Recife, V. 5, p. 49-58, 1941.

RIBEIRO, Darcy. O livro dos CIEPs. Rio de Janeiro: Bloch Editores, 1986.

ROLLEMBERG, Denise; MARTINS FILHO, João Roberto. Esquecimento das memórias: o golpe de 1964 e o regime militar. São Carlos: Ed. UFSCar, 2006.

ROMANELLI, Otaíza de Oliveira. História da educação no Brasil. 5. ed. Petrópolis: Vozes, 1984. 
SAVIANI, Dermeval. Instituições escolares: conceito, história, historiografia e práticas. Cadernos de História da Educação, Uberlândia, v. 4, p. 27-33, 2005.

SILVA, Odemir Capistrano. Aqueles anos verdes da nossa história. Revista pilares da história: textos sobre a história de Duque de Caxias e da Baixada Fluminense. Duque de Caxias: CMDC, 2003.

SOUSA, Joaquim Moreira de. [Correspondência]. Destinatário: Armanda Alberto. Ceará, 9 de jul. 1934. 2 f. 2 carta pessoal.

SOUSA, Joaquim Moreira de. [Correspondência]. Destinatário: Armanda Alberto. Ceará, 4 de set. 1924. 2 f. 1 carta pessoal.

TAVARES, Mauricio Antunes. Para livrar o campo do amarelão, da maleita, do alcoolismo e do ofidismo. A educação rural em Pernambuco nos anos 1930 a 1950. Educar em Revista, Curitiba, v. 30, n. 54, p. 141-157, 2014. Disponível em:

http://www.scielo.br/pdf/er/n54/aogn54.pdf. Acesso em: 30 abr. 2021.

TORRES, Alberto. A organização nacional. Brasília, DF: EdUnB, 1982.

WERLE, Flávia Obino Corrêa; SÁ BRITTO, Lenir Marina Trindade de; COLAU, Cinthia Merlo. Espaço escolar e história das instituições escolares. Revista Diálogo Educacional, Curitiba, v. 7, n. 22, p. 147-163, 2007.

XAVIER, Libânia; CUNHA, Luiz Antônio. Associação Brasileira de Educação. In: ABREU, Alzira Alves et al. Dicionário Histórico-Biográfico Brasileiro pós 1930. Rio de Janeiro: Editora FGV/CPDOC, 2001. v. 1. p. 390-391.

Universidade do Estado de Santa Catarina - UDESC

Programa de Pós-Graduação em Educação - PPGE

Revista Linhas

Volume 22 - Número 50 - Ano 2021 revistalinhas@gmail.com 